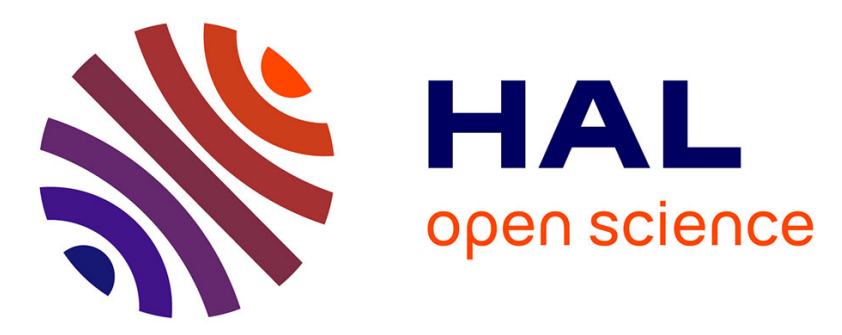

\title{
OhrRA functions as a redox-responsive system controlling toxinogenesis in Bacillus cereus
}

Gérémy Clair, Alain Lhorphelin, J. Armengaud, Catherine Duport

\section{To cite this version:}

Gérémy Clair, Alain Lhorphelin, J. Armengaud, Catherine Duport. OhrRA functions as a redoxresponsive system controlling toxinogenesis in Bacillus cereus. Journal of Proteomics, 2013, 94, pp.527539. 10.1016/j.prot.2013.10.024 . hal-02642402

\section{HAL Id: hal-02642402 https://hal.inrae.fr/hal-02642402}

Submitted on 28 May 2020

HAL is a multi-disciplinary open access archive for the deposit and dissemination of scientific research documents, whether they are published or not. The documents may come from teaching and research institutions in France or abroad, or from public or private research centers.
L'archive ouverte pluridisciplinaire HAL, est destinée au dépôt et à la diffusion de documents scientifiques de niveau recherche, publiés ou non, émanant des établissements d'enseignement et de recherche français ou étrangers, des laboratoires publics ou privés. 


\title{
OhrRA functions as a redox-responsive system controlling toxinogenesis in Bacillus cereus
}

\author{
Gérémy Clair ${ }^{a, b, c}$, Alain Lorphelin ${ }^{c}$, Jean Armengaudc, Catherine Duport ${ }^{a, b, *}$ \\ âniversité d'Avignon et des Pays de Vaucluse, UMR408, Sécurité et Qualité des Produits d'Origine Végétale, F-84000 Avignon, France \\ bINRA, UMR408, Sécurité et Qualité des Produits d’Origine Végétale, F-84914 Avignon, France \\ 'Laboratoire de Biochimie des Systèmes Perturbés, CEA Marcoule, DSV-iBEB-SBTN-LBSP, F-30207 Bagnols-sur-Cèze cedex, France
}

Keywords:

Comparative exoproteome

Bacillus cereus

Anaerobiosis

Redox

Virulence

\section{A B S T R A C T}

Bacillus cereus OhrR is a member of the subgroup of the MarR (multiple antibiotic resistance) family of transcriptional regulators that use a cysteine-based redox sensing mechanism. OhrA is a thiol-dependent, peroxidase-like protein. The dual OhrRA system triggers B. cereus adaptation in response to redox changes, such as those encountered in the environment of the gastrointestinal tract. Here, we investigated the role of OhrRA in toxinogenesis. Comparative shotgun analysis of exoproteomes from $\Delta \mathrm{ohr} A, \Delta \mathrm{ohr} R$ and wild-type cells revealed significant changes in the abundance levels of toxin-related proteins depending on the extracellular redox potential. We complemented these data by measuring the DNA binding activity of reduced and oxidized recombinant OhrR on toxin and putative toxin promoter regions. Furthermore, transcriptomic data and OhrRAdependent, antiproliferative activity of the B. cereus exoproteome on Caco-2 human epithelial cells were recorded. The results indicate that OhrR controlled toxin gene expression directly or indirectly in a redox- and toxin-dependent manner, and may function as a repressor or an activator. Moreover, we found that OhrR restricts toxindependent antiproliferative activity of the B. cereus exoproteome whatever the growth conditions, while the restrictive impact of OhrA occurs only under low ORP anoxic conditions.

\section{Biological significance}

B. cereus is a notorious foodborne pathogen which causes gastroenteritis. Fatal and severe cases have been reported. The pathogenicity of $B$. cereus is intimately associated with the production of epithelial cell-destructive toxins in the small intestine. The small intestine poses several challenges for a pathogen because it is sliced into various niches with different oxygen concentrations and different redox potentials. We recently showed that the organic hydroperoxide resistance OhrRA system was crucial to the successful adaptation of B. cereus to extreme redox environments such as those encountered in the lumen (high reducing anoxic environment) and on the intestinal epithelium (transient oxic environment). Here we provide evidence that this bacterial system is a major virulence determinant in B. cereus in that it coordinates toxinogenesis in a redox dependent manner. Specifically, our comparative exoproteomic analyses reveal that OhrR strongly restricts B. cereus toxinogenesis under high reducing anoxic conditions while OhrA boosts toxinogenesis. Based on exoproteomic analyses, we further examined the role of $\mathrm{OhrR}$ and found that it functions as a

\footnotetext{
* Corresponding author. Tel.: +33 432722 507; fax: +33 432722492.

E-mail address: catherine.duport@univ-avignon.fr (C. Duport).
} 
redox-dependent transcriptional regulator of toxin and putative toxin genes. These findings provide novel insights into the weapons used by B. cereus to control its toxinogenic potential and, as a result its toxicity against human epithelial cells.

\section{Introduction}

Bacillus cereus is a ubiquitous, globally distributed, foodborne pathogen. This human pathogen [1,2] is mainly associated with two types of gastrointestinal (GI) infection, both causing diarrhea and vomiting after the ingestion of contaminated food. The diarrheal syndrome is mainly attributed to toxins secreted by vegetative cells colonizing the human small intestine [3-5]. A total of 14 toxin-related proteins were identified in the culture supernatant of B. cereus cells grown in low oxidoreduction potential (ORP) anoxic conditions, which are considered to mimic those encountered in the human intestine [6]. These 14 toxin-related proteins include the four components (HblL1, HblL2, $\mathrm{HblB}$ and $\left.\mathrm{HblB}^{\prime}\right)$ of hemolysin $\mathrm{BL}(\mathrm{Hbl})$, the three components (NheA, NheB, NheC) of the nonhemolytic enterotoxin, Nhe, and the single-component protein, CytK [5,7-9]. Hbl, Nhe and CytK are secreted, pore-forming cytotoxins, which are currently considered to be the main causative agents of diarrheal syndrome [9-11]. However, several other toxin-related proteins may contribute to this syndrome, including hemolysin I (cereolysin O, HlyI), which is a thiol-activated, cholesterolbinding cytolysin, hemolysin II (HlyII) and enterotoxin FM (EntFM) [12-17]. Enterotoxin-like EntA, EntB and EntC, which are not regulated by the pleiotropic virulence gene regulator $\mathrm{PlcR}$, cannot be excluded as causative agents of diarrheal syndrome [6]. Although toxin-related proteins most probably play a prevalent role in $B$. cereus pathogenicity, other proteins present in the extracellular milieu may be required, such as components of flagella [18], cell-wall peptidases [13,19,20], metalloproteases [21], antioxidant enzymes [22], siderophores for iron acquisition from the host [23] and moonlighting proteins [24-26]. All of these exoproteins are classified as virulence factors and constitute the major part of the B. cereus exoproteome as observed by shotgun, high-throughput methodology $[6,27]$.

The regulation of $B$. cereus toxin gene expression mobilizes a complex machinery [28] that includes several pleiotropic regulators, such as the PlcR-PapR quorum sensing system $[29,30]$, the CodY repressor [31], the ferric uptake regulator Fur [32], the catabolite control protein A (CcpA) [33], the two-component regulatory system ResDE, and the redox regulator Fnr. ResDE and Fnr are also involved in maintaining redox homeostasis by regulating catabolism [34-38]. Like ResDE and Fnr, the OhrRA system is involved in redox homeostasis [39]. Unlike ResDE and Fnr, the involvement of OhrRA in toxinogenesis has not been yet reported in the literature. The $B$. cereus OhrRA system comprises OhrA (organic hydroperoxide resistance protein A), an antioxidant protein, and OhrR, a potential pleiotropic regulator belonging to the MarR (multiple antibiotic resistance) family of winged, helix-turn-helix, DNA-binding proteins $[40,41]$. However, B. cereus OhrR appears to be an atypical member of this family because it contains four cysteine residues at its $\mathrm{N}$-terminal domain while most members have two cysteines [39].

Here, we investigated the impact of B. cereus OhrR and OhrA on toxinogenesis. We compared the exoproteomes of
$\Delta$ ohrA and $\Delta$ ohrR mutants with their parental strains from cells grown under three different ORP - one under aerobiosis and two under anaerobiosis. We found that OhrRA controls the toxinogenic profile of B. cereus. The effect of OhrRA on the production of toxin-related proteins is mediated at both the transcriptional (mainly by $\mathrm{OhrR}$ ) and post-transcriptional (mainly by OhrA) levels. OhrR restricts toxin-dependent, antiproliferative activity of the $B$. cereus exoproteome on Caco-2 cells whatever the growth conditions, while OhrA restricts this activity only under low-ORP anaerobiosis.

\section{Materials and methods}

\subsection{Bacterial strains and growth conditions}

Escherichia coli BL21 CodonPlus(DE3)-RIL (Stratagene) was used for the heterologous production of OhrR. B. cereus ATCC 14579 was used as the parental strain [42]. Strains lacking OhrA ( $\Delta$ ohrA) and OhrR ( $\Delta$ ohrR) were constructed previously [6]. Wild-type and mutant strains were grown in $\mathrm{pH}$-regulated batch cultures on glucose-containing MOD medium $[43,44]$ under low-ORP anaerobiosis (initial ORP $=-410 \mathrm{mV}, \mathrm{pO}_{2}=0 \%$ ), high-ORP anaerobiosis (iORP $=-10 \mathrm{mV}, \mathrm{pO}_{2}=0 \%$ ) and full aerobiosis (iORP $=+140 \mathrm{mV}$, $\mathrm{pO}_{2}=100 \%$ ), as previously described [39]. Supernatants were collected at the log/exponential growth phase, i.e. $1.5 \mathrm{~h}$ after reaching the maximal growth rate (when $\mu=80( \pm 10) \%$ of $\mu_{\max }$ ). After growth, the culture supernatants were first filtered through a 45 - $\mu \mathrm{m}$-pore-size, low-adsorption, cellulose-acetate membrane filter (Sartorius) and then through a $20-\mu \mathrm{m}$-pore-size filter. Filtered fractions $(40 \mathrm{~mL})$ were quickly frozen and kept at $-20{ }^{\circ} \mathrm{C}$ until use.

\subsection{Relative quantification of gene expression using real time RT-PCR}

RT-PCR was performed using SYBR Green technology on a Lightcycler instrument (Roche applied Science) as described previously [34]. The primers used in this study are shown in Table S1.

\subsection{Exoprotein sample preparation and nanoLC-MS/MS analysis}

Three independent biological replicates were harvested for each of the three conditions (aerobiosis, low- and high-ORP anaerobiosis) and three strains (wild-type, and $\Delta$ ohrA and $\Delta$ ohrR mutant strains). Extracellular proteins were extracted from the 27 culture supernatants, subjected to SDS-PAGE, and then identified after trypsin proteolysis and nanoLC-MS/MS tandem mass spectrometry, as previously described [6]. The MASCOT search engine (version 2.2.04) was used to search all MS/MS spectra against an in-house polypeptide sequence database containing the sequence of all annotated proteins 
encoded by the B. cereus ATCC 14579 chromosome (NC_004722) and plasmid pBClin15 (NC_004721). This database comprises 5255 polypeptide sequences, totaling 1,455,982 amino acids. Searches for tryptic peptides were performed with the following parameters: full-trypsin specificity, a mass tolerance of $10 \mathrm{ppm}$ on the parent ion and 0.6 Da on the MS/MS, static modifications of carboxyamidomethylated Cys (+57.0215), and dynamic modifications of oxidized Met (+15.9949). The maximum number of missed cleavages was set at 2 . All peptide matches with a peptide score below a $p$-value of 0.01 were filtered by the IRMa 1.21.0 parser [45]. A protein was considered to be validated when at least two different peptides were detected in the same experiment. The false-positive rate for protein identification was estimated using the appropriate decoy database to be below $0.1 \%$ with such stringent parameters. The MS/MS data were deposited in the PRIDE Proteomics Identifications database (http://www.ebi.ac.uk/pride/) under accession numbers 2720927211 via the ProteomeXchange platform (ProteomeXchange DOI: http://dx.doi.org/10.6019/PXD000024).

\subsection{Spectral count-based protein quantification and statistical analysis}

The number of MS/MS spectra per protein recorded by nanoLC-MS/MS was extracted for each biological triplicate for all three growth conditions assayed. Proteins were further considered for comparison only if peptides were detected in at least two of the three replicates. The resulting datasets were normalized taking into account the total protein concentration of the corresponding supernatant. Protein concentrations in $B$. cereus were determined using the Reducing agent Compatible Detergent Compatible (RCDC) protein assay (Bio-Rad) following the supplier's instructions. MS/MS spectral counts were compared with the TFold method using the PatternLab software program 2.0.0.13 [46]. Fold-change and $p$-value cutoffs were set at 2 and 0.05 , respectively. $\log _{2}$ (fold-change) was then calculated for comparison. Principal component analysis (PCA) was carried out using Tanagra software 1.4.44 [47].

\subsection{Recombinant overexpression of ohrR and protein purification}

B. cereus OhrR was produced as a C-terminal His-tagged protein using E. coli BL21(pET101ohrR). For this, the coding sequence for ohrR was PCR amplified from B. cereus ATCC 14579 genomic DNA using the primers, ohrE1 and ohrE2 (Table S1). The amplicon was cloned as a blunt-end PCR product into pET101/D-TOPO, yielding pET101ohrR. E. coli BL21 CodonPlus(DE3)-RIL(pET101ohrR) recombinant cells were grown until the $\mathrm{OD}_{600}$ reached $\sim 0.7$. Protein overproduction was then triggered with $1 \mathrm{mM}$ isopropyl- $\beta-D-$ thiogalactopyranoside. After incubation for $4 \mathrm{~h}$, cells were harvested by centrifugation $\left(10,000 \mathrm{~g}\right.$ for $10 \mathrm{~min}$ at $\left.4{ }^{\circ} \mathrm{C}\right)$ and suspended in $50 \mathrm{mM}$ Tris-HCl buffer (pH 7.9) containing $200 \mathrm{mM}$ $\mathrm{NaCl}, 5 \mathrm{mM}$ imidazole and supplemented with benzonase (25 units per $\mathrm{mL}$ in the presence of $1 \mathrm{mM} \mathrm{MgSO}_{4}$ ) and Complete free EDTA (Roche) protease inhibitors (1 $\mathrm{mg}$ per $\mathrm{mL}$ ). Cells were lysed by disruption at $0.9 \mathrm{kbar}$ using a OneShot cell disruptor (Constant System). Cell debris and membrane particles were removed by centrifugation at $20,000 \mathrm{~g}$ for $20 \mathrm{~min}$ at $4^{\circ} \mathrm{C}$. The resulting supernatant was loaded onto a HisTrap HP $5 \mathrm{~mL}$ column (GE Healthcare) operated at $4{ }^{\circ} \mathrm{C}$ with an Äkta Purifier 10 system (Amersham Biosciences), as previously described [48,49]. The recombinant OhrR protein was eluted and desalted on a HiPrep ${ }^{\mathrm{TM}}$ 26/10 Desalting column (GE Healthcare) previously equilibrated with $50 \mathrm{mM}$ Tris- $\mathrm{HCl}$ buffered at $\mathrm{pH} 7.9$ and containing $50 \mathrm{mM}$ $\mathrm{NaCl}$. The purity of the protein was estimated as $98 \%$ by SD200 gel filtration chromatography and UV signal integration. The protein concentration $(1.2 \mathrm{mg} / \mathrm{mL})$ was determined using a Bradford assay (Interchim) with bovine serum albumin as the reference. Protein was stored at $-80^{\circ} \mathrm{C}$ until analysis.

\subsection{Dynamic light scattering (DLS)}

To evaluate the quaternary structure of OhrR in solution, purified protein sample was concentrated on an Ultracell YM10 microcon (Millipore) device to $2.4 \mathrm{mg} / \mathrm{mL}$. An $80 \mu \mathrm{L}$ sample of OhrR was loaded onto a $24 \mathrm{~mL}$ Superdex 200 10/300 GL column (GE Healthcare) previously equilibrated with $50 \mathrm{mM}$ $\mathrm{KH}_{2} \mathrm{PO}_{4} / \mathrm{Na}_{2} \mathrm{HPO}_{4}$ buffered at $\mathrm{pH} 7.4$ and containing $150 \mathrm{mM}$ $\mathrm{NaCl}$. The column was operated at a flow rate of $0.5 \mathrm{~mL} / \mathrm{min}$ with the same buffer on an Agilent 1100 series, reverse-phase HPLC system equipped with a G1322A degasser, G1311A quaternary pump, and G1313A autosampler. The elution profile was monitored with a G1315B diode array detector (Agilent), a miniDawn Tristar multiangle laser static light scattering detector (three angles: $45^{\circ}, 90^{\circ}$, and $135^{\circ}$ ) coupled to a DynaPro Titan light-scattering instrument (Wyatt Technology) placed at $90^{\circ}$, and an Optilab rEX differential refractometer (Wyatt Technology). The $90^{\circ}$ multiangle light-scattering detector was calibrated with pure toluene, and bovine serum albumin was then used to normalize the other detectors $\left(45^{\circ}\right.$ and $\left.135^{\circ}\right)$ in the corresponding buffer. Light scattering data were analyzed using ASTRA software (Wyatt technology).

\subsection{Nonreducing SDS-PAGE}

The presence and formation of disulfide bonds were monitored by nonreducing SDS-PAGE. Reduced protein samples were prepared by incubating $\operatorname{OhrR}(20 \mathrm{mg} / \mathrm{L})$ with 1 to $100 \mu \mathrm{M}$ dithiothreitol (DTT) for $30 \mathrm{~min}$ at $37^{\circ} \mathrm{C}$. Excess DTT was then removed by ultrafiltration. Oxidized OhrR was obtained by incubating reduced protein samples for $30 \mathrm{~min}$ at $37^{\circ} \mathrm{C}$ with either $5 \mathrm{nM}$ or $500 \mu \mathrm{M}$ cumene hydroperoxide (CHP) or $1 \mu \mathrm{M}$ $\mathrm{H}_{2} \mathrm{O}_{2}$. To test the reducing effect of LMW thiols and dihydrolipoic acid, purified OhrR was first treated with $50 \mu \mathrm{M}$ CHP as described above, and then incubated for 30 min with increasing concentrations ( $0.05 \mathrm{mM}$ to $25 \mathrm{mM}$ ) of either cysteine (Cys, Sigma), bacillithiol (BSH, JEMA Biosciences), coenzyme A (CoASH, Sigma) or dihydrolipoic acid (DHLA, Sigma). Protein samples were then subjected to electrophoresis on nonreducing novex NuPAGE® SDS-PAGE 4-12\% polyacrylamide gels (Invitrogen) and stained with SimplyBlue ${ }^{\text {TM }}$ SafeStain (Invitrogen).

\subsection{Electromobility shift assays (EMSAs)}

Nucleic acid fragments containing the promoter regions of ohrRA, nhe, hbl, hblB, entA, entB, entC, hlyI, hlyII, entFM and cytK were PCR-amplified using biotinylated forward primers and nonbiotinylated reverse primers (listed in Table S6). The DNA 
Version définitive du manuscrit publiée dans / Final version of the manuscript published in :

Journal of Proteomics (2013), Vol. 94, p. 527-539, DOI: 10.1016/j.prot.2013.10.024

Journal homepage: www.elsevier.com/locate/jprot

used as a negative control was a fragment of the ssuRNA BC0007 sequence (NC_004722) that was amplified with the biotinylated ssubiof and ssuR primer pair. The 5'-labeled amplicons were purified using the High Pure PCR Product Purification Kit (Roche). Binding reactions were performed for $30 \mathrm{~min}$ at $37{ }^{\circ} \mathrm{C}$ by incubating biotin-labeled DNA fragments (2 nM per reaction) with either $0.05,0.1,0.2,0.4,0.8,1$ or $2 \mu \mathrm{M}$ reduced OhrR (with $100 \mu \mathrm{M} \mathrm{DTT}$ ) in $10 \mathrm{mM}$ Tris-HCl buffered at pH 7.5 and containing $50 \mathrm{mM} \mathrm{KCl}, 2.5 \%$ glycerol, $5 \mathrm{mM}$ $\mathrm{MgCl}_{2}$ and $5 \mathrm{mg} / \mathrm{L}$ poly(dI- $\mathrm{dC}$ ). The samples were resolved by electrophoresis on a $6 \%$ nondenaturing polyacrylamide gel and electrotransferred onto Hybond $\mathrm{N}+$ Nylon membranes (Amersham). Biotin-labeled DNA was detected using the LightShift Chemiluminescent EMSA Kit (Pierce). Oxidized OhrR was obtained by adding $50 \mu \mathrm{M}$ CHP to the binding buffer. The DNA binding activity of oxidized OhrR was assayed in the presence of LMW thiol with $5 \mathrm{mM}$ cysteine added to the binding buffer.

\subsection{Growth inhibition tests with human Caco-2 cells}

Growth inhibition of human Caco-2 cells with filtrate supernatants from aerobic, high and low-ORP anaerobic B. cereus cultures was assayed as previously described [6]. For each of the nine biological samples, growth inhibition tests were assayed twice.

\section{Results}

\subsection{Exoproteome analysis of $B$. cereus $\Delta \mathrm{ohrR}$ and} $\Delta$ ohrA cells

Toxins are extracellular proteins and are the main components of the B. cereus exoproteome [6]. To determine whether OhrRA contributes to toxin production, we identified changes in the exoproteomes of $\Delta \mathrm{ohrR}$ and $\Delta \mathrm{ohr} \mathrm{A}$ mutants in comparison with the wild-type strain [6,27]. For this, cells were grown in $\mathrm{pH}$-regulated batch cultures on glucose-containing medium under low-ORP anaerobiosis, high-ORP anaerobiosis and full aerobiosis. Three independent biological replicates were harvested for each of the three conditions and three strains. Extracellular proteins were extracted from the 27 culture supernatants and then identified and quantified by tandem mass spectrometry with a high-resolution LTQ-Orbitrap XL mass spectrometer. A dataset comprising 171,776 MS/MS spectra was recorded for the 27 samples. A total of 65,579 different spectra were confidently assigned to $B$. cereus peptides, resulting in the identification of 181 proteins (Table S2). The number of MS/MS spectra assigned to each protein was normalized for comparison using the protein concentration of the samples (Table S3). We reported the fold-change observed for each detected protein, taking into account spectral counts as input (Table S4). We systematically performed blast analyses to annotate wronggene functional assignments and to retrieve missing functions. The detected proteins were catalogued into five functional groups: 1) toxins, 2) degradative enzymes, 3) flagella components, 4) metabolism, and 5) others. The latter, which comprised less than $5 \%$ of the detected proteins, includes proteins
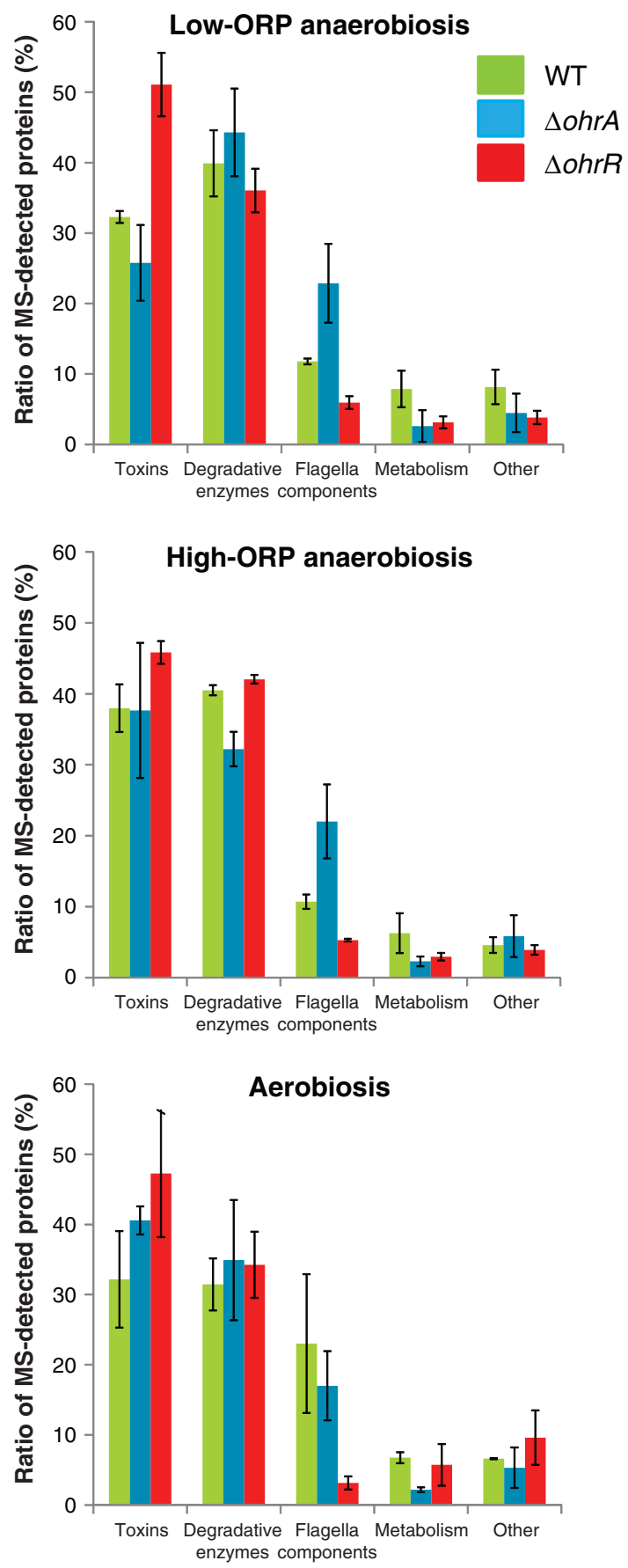

Fig. 1 - Distribution of exoproteins in terms of function. The diagrams indicate the mean ratio of MS/MS spectra assigned to proteins classified into functional categories for the exoproteomes from wild-type (green), $\triangle$ ohrA (blue) and $\triangle$ ohrR (red) cells grown under low-ORP anaerobiosis, high-ORP anaerobiosis, and aerobiosis. See Table S3 for details on the mean ratio estimated from triplicate independent experiments. Statistical differences between wild-type and mutant strains were evaluated with a Student's t-test. ${ }^{*}=$ $P<0.05$.

associated with defense mechanisms, transport and membrane biogenesis, translation and transcription, and proteins without functional assignment. Fig. 1 and Table S4 show that the global 
distribution of proteins among these five functional groups was significantly different in the mutant strains compared with the wild-type strain. This was observed whatever the growth condition. Specifically, the $\Delta$ ohrR exoproteome exhibited a higher toxin content but lower flagella component content in the three conditions tested. The disruption of ohrA significantly decreases the toxin content of low-ORP anaerobically grown cells and increases the flagella component content. These results indicate that OhrR and OhrA modulate the B. cereus exoproteome in a redox-dependent manner.

\subsection{Impact of OhrR and OhrA on exoprotein-specific changes}

\subsubsection{Evidence for novel exoproteins}

Detailed analysis of the $\Delta \mathrm{ohr}$ A or $\Delta \mathrm{ohr}$ exoproteomes revealed the presence of 40 additional proteins compared with the parental strain exoproteome (Table S3). A total of 8 and 20 proteins were found exclusively in the $\Delta \mathrm{ohr} A$ and $\Delta \mathrm{ohr} R$ exoproteomes, respectively. Among these, one and three proteins of unknown functions - annotated as NP_832962.1, and NP_831667.1, NP_834698.1 and NP_831845.1 - were shown to be abundant components of the $\Delta o h r A$ and $\Delta o h r R$ exoproteomes, respectively. NP_832962.1 encompasses an LPXTG-motif and shows similarities to a cell wall anchor domain. NP_831667.1 is annotated as a phage protein. NP_834698.1 exhibits similarities with the ErfK/YkuD LD-transpeptidase catalytic domain (COG1376) and could be involved in peptidoglycan crosslinking. NP_831845.1 belongs to the uncharacterized COG4842 orthologous group and shows some similarities to the small ESAT-6 protein that has been characterized as central to virulence and protective immunity in Mycobacterium tuberculosis [50].

\subsubsection{Focus on toxin-related proteins}

Table 1 lists the abundance level changes of toxin-related proteins in $\Delta$ ohrR and $\Delta$ ohrA mutants. We noted that (i) the abundance levels of $\mathrm{Hbl}$ and Nhe components significantly decreased in $\Delta$ ohrA cells and increased in $\Delta$ ohrR cells when grown under low-ORP anaerobiosis, (ii) the HlyI abundance level was significantly decreased in the $\Delta$ ohrA exoproteome, whatever the conditions, (iii) HlyII was significantly more abundant in $\Delta$ ohrR than in the wild-type exoproteome under low-ORP anoxic conditions, (iv) EntFM was more highly represented in the $\Delta \mathrm{ohr} R$ exoproteome, whatever the conditions, and (v) EntB was not detected in the absence of OhrR, whatever the growth conditions (Table S3), explaining the strong decrease reported in Table 1. In contrast, EntC and EntA, which are structurally related to EntB [6], showed higher abundance levels in the $\Delta$ ohrR exoproteome than in the wild-type exoproteome. These results indicate that both OhrA and OhrR regulates the quantity of toxin-related proteins in the $B$. cereus exoproteome in an ORP-dependent manner.

\subsection{Dual role of B. cereus OhrR as a repressor and an activator of toxin gene expression}

Based on (i) the functions of its orthologs [51], (ii) our previous proteomic data [39], and (iii) our exoproteomic results, we believe that OhrR, unlike OhrA, controls the toxin content of the $B$. cereus exoproteome at the transcriptional level. We thus quantified the expression of operons or genes encoding toxin-related proteins in wild-type and $\Delta$ ohrR and $\Delta$ ohrA cells using RT-PCR. Fig. 2 associates the mRNA level changes with the protein level changes in mutant strains relative to the wild-type strain. As expected, there is no correlation between protein and mRNA level variations of the toxin genes in the $\Delta$ ohrA mutant, suggesting that OhrA-dependent toxin secretion may occur mainly at the post-transcriptional level, whatever the redox conditions. However, the variations of mRNA levels are consistent with proteomic data in the $\Delta$ ohrR mutant, with some exceptions: (i) HlyI and CytK in the three culture conditions tested, (ii) HlyII under both high-ORP anaerobiosis and aerobiosis, and (iii) NheC under aerobiosis. This characteristic distinguishes these four toxins from the others and suggests that OhrR-dependent regulation of the HlyII, HlyI, CytK and NheC abundance level may occur mainly at the post-transcriptional level in these growth conditions. Moreover, the results indicate that OhrR may act as a transcriptional activator of entB and a repressor of hblABC, nheA, nheB, hblB, entFM, entA and entC, whatever the conditions.

\subsection{B. cereus OhrR is mainly a noncovalent dimer in its reduced form and a covalent dimer in its oxidized form}

Orthologs of B. cereus OhrR regulate their target genes by directly binding to the operator site located in the vicinity of its target promoters [52]. To investigate whether B. cereus OhrR may bind to toxin-related protein gene promoters in in vitro experiments, ohrR was expressed in E. coli and purified as a recombinant, His-tagged protein. The $M_{r}$ of the purified polypeptide, as estimated by SDS-PAGE under reducing conditions, was $\sim 20 \mathrm{kDa}$ as expected (Fig. S1). Its native quaternary structure was monitored by gel filtration coupled to a Multi-Angle laser Light Scattering (MALS) detector. The protein behaved as a relaxed homodimer in solution with a molecular weight estimated at $42( \pm 1) \mathrm{kDa}$ and a hydrodynamic radius of $3.2( \pm 0.3) \mathrm{nm}$ (Fig. S2). Nonreducing SDS-PAGE revealed an abundant protein band corresponding to OhrR monomer and a doublet corresponding to OhrR covalently linked dimer (Fig. 3A). Taken together, these data indicate that the dimeric OhrR population detected by Dynamic Light Scattering (DLS) is a mixed population comprising mainly noncovalently associated subunits, but also covalent dimers corresponding to oxidized forms of OhrR. Moreover, covalent dimers could adopt two conformations differing in terms of rigidity, with the more relaxed structure migrating more slowly than the rigid structure. To test the ability of noncovalent OhrR dimer to convert into covalent dimer, purified protein $(20 \mu \mathrm{M})$ was treated with the oxidizing agent, cumene hydroperoxide (CHP). Fig. 3A shows the CHP dose-dependent formation of rigid, covalently linked OhrR dimers as analyzed by SDS-PAGE in nonreducing conditions. Increasing the concentration of CHP from $5 \mu \mathrm{M}$ to $50 \mathrm{mM}$ led to the disappearance of the protein band corresponding to OhrR monomer and a concomitant increase in the amount of the faster-migrating band corresponding to a covalent dimer. Moreover, at the highest CHP concentrations, we observed faint bands corresponding to tetrameric and octomeric species. Interestingly, only the slower-migrating band corresponding to covalently linked OhrR dimer in a relaxed form was detected after treatment with $500 \mathrm{mM}$ CHP. In addition, the tetrameric 
Table 1 - Fold-changes in abundance levels ( $\log _{2}$ ratio) of exoproteins classified as toxins.

\begin{tabular}{|c|c|c|c|c|c|c|c|c|c|c|c|c|c|c|}
\hline \multirow{3}{*}{ Protein } & \multirow{3}{*}{ Functional annotation } & \multirow{3}{*}{ Accession } & \multicolumn{6}{|c|}{$\Delta$ ohrA versus wild-type ${ }^{a}$} & \multicolumn{6}{|c|}{$\Delta$ ohrR versus wild-type ${ }^{a}$} \\
\hline & & & \multicolumn{2}{|c|}{$\begin{array}{c}\text { Low ORP } \\
\text { anaerobiosis }\end{array}$} & \multicolumn{2}{|c|}{$\begin{array}{c}\text { High ORP } \\
\text { anaerobiosis }\end{array}$} & \multicolumn{2}{|c|}{ Aerobiosis } & \multicolumn{2}{|c|}{$\begin{array}{c}\text { Low ORP } \\
\text { anaerobiosis }\end{array}$} & \multicolumn{2}{|c|}{$\begin{array}{c}\text { High ORP } \\
\text { anaerobiosis }\end{array}$} & \multicolumn{2}{|c|}{ Aerobiosis } \\
\hline & & & $\log _{2}$ ratio & $p$-Value & $\log _{2}$ ratio & $p$-Value & $\log _{2}$ ratio & $p$-Value & $\log _{2}$ ratio & $p$-Value & $\log _{2}$ ratio & $p$-Value & $\log _{2}$ ratio & $p$-Value \\
\hline $\mathrm{Hbl2}$ & Enterotoxin HBL component L2 & NP_832847 & -0.796 & 0.058 & 1.412 & 0.107 & 1.138 & 0.028 & 2.816 & 0.001 & 2.160 & 0.003 & 1.503 & 0.059 \\
\hline Hbl1 & Enterotoxin HBL component L 1 & NP_832846 & -1.546 & 0.000 & -0.286 & 0.240 & 0.324 & 0.259 & 1.613 & 0.000 & 1.082 & 0.011 & 0.507 & 0.190 \\
\hline HblB & Enterotoxin HBL component B & NP_832845 & -0.332 & 0.020 & 1.990 & 0.069 & 0.918 & 0.048 & 2.699 & 0.001 & 2.235 & 0.000 & 1.241 & 0.072 \\
\hline $\mathrm{HblB}^{\prime}$ & Enterotoxin HBL component B' & NP_832844 & -3.236 & 0.000 & -0.902 & 0.087 & -0.253 & 0.052 & 1.401 & 0.001 & 0.817 & 0.075 & 0.219 & 0.362 \\
\hline NheA & Enterotoxin Nhe component A & NP_831582 & -0.977 & 0.021 & 0.189 & 0.371 & 0.668 & 0.142 & 1.843 & 0.000 & 1.564 & 0.005 & 1.275 & 0.008 \\
\hline NheB & Enterotoxin Nhe component B & NP_831583 & -0.995 & 0.008 & 0.034 & 0.473 & 0.356 & 0.283 & 1.690 & 0.000 & 1.423 & 0.005 & 0.957 & 0.030 \\
\hline NheC & Enterotoxin Nhe component C & NP_831584 & -2.568 & 0.000 & -0.417 & 0.261 & -0.771 & 0.004 & 2.169 & 0.001 & 1.724 & 0.029 & 1.395 & 0.076 \\
\hline CytK & Cytotoxin $\mathrm{K}$ & NP_830896 & -0.801 & 0.010 & -0.294 & 0.326 & 0.966 & 0.030 & -0.023 & 0.474 & -1.245 & 0.028 & -3.983 & 0.003 \\
\hline HlyI & Hemolysin I & NP_834769 & -3.035 & 0.000 & -1.609 & 0.001 & -0.690 & 0.020 & -0.247 & 0.161 & -0.058 & 0.459 & -0.826 & 0.000 \\
\hline HlyII & Hemolysin II & NP_833256 & 5.795 & 0.187 & 0.082 & 0.469 & 0.226 & 0.394 & 6.343 & 0.047 & 0.785 & 0.219 & -0.272 & 0.136 \\
\hline EntFM & Enterotoxin & NP_831723 & -0.530 & 0.031 & 0.416 & 0.141 & 0.088 & 0.328 & 1.209 & 0.002 & 1.444 & 0.001 & 0.936 & 0.000 \\
\hline EntA & Enterotoxin-like & NP_834902 & 0.966 & 0.219 & 1.232 & 0.053 & 1.547 & 0.013 & 2.286 & 0.000 & 2.024 & 0.000 & 1.953 & 0.000 \\
\hline EntB & Enterotoxin-like & NP_832699 & -0.983 & 0.043 & -0.624 & 0.026 & -0.122 & 0.313 & -4.617 & 0.000 & -4.079 & 0.000 & -7.795 & 0.000 \\
\hline EntC & Enterotoxin-like & NP_830603 & 1.149 & 0.192 & 2.078 & 0.016 & 1.895 & 0.023 & 2.800 & 0.001 & 2.129 & 0.001 & 2.051 & 0.004 \\
\hline
\end{tabular}

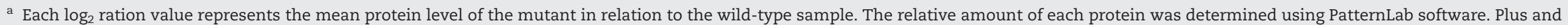
minus symbols indicate up- and down-regulation of the protein, respectively. Numbers in bold indicate data that satisfied statistical criteria $(p$-value $<0.05)$ 
Version définitive du manuscrit publiée dans / Final version of the manuscript published in :

Journal of Proteomics (2013), Vol. 94, p. 527-539, DOI: 10.1016/j.prot.2013.10.024

Journal homepage: www.elsevier.com/locate/jprot

\begin{tabular}{|c|c|c|c|}
\hline & Low-ORP anaerobiosis & High-ORP anaerobiosis & Aerobiosis \\
\hline$\Delta o h r A$ & 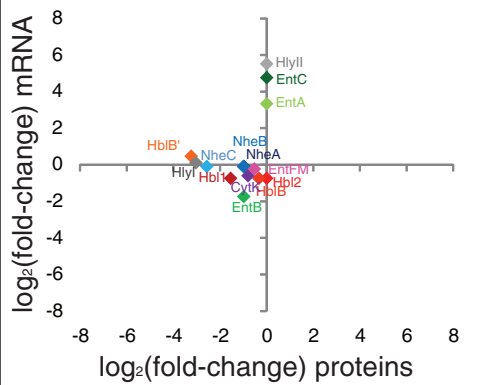 & 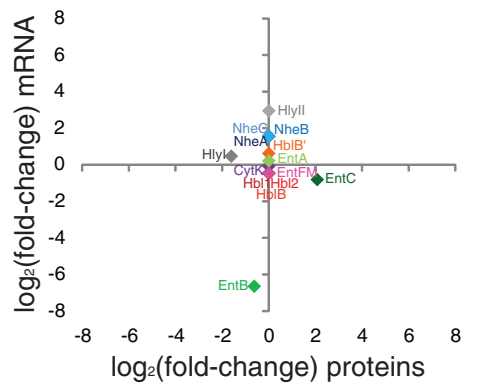 & 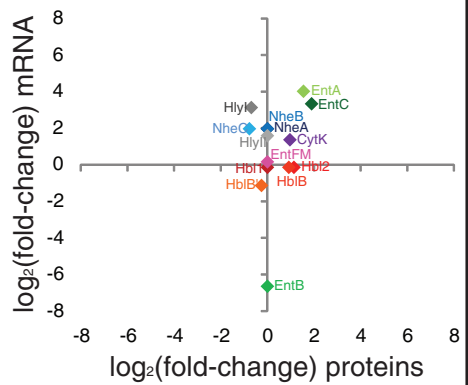 \\
\hline$\Delta o h r R$ & 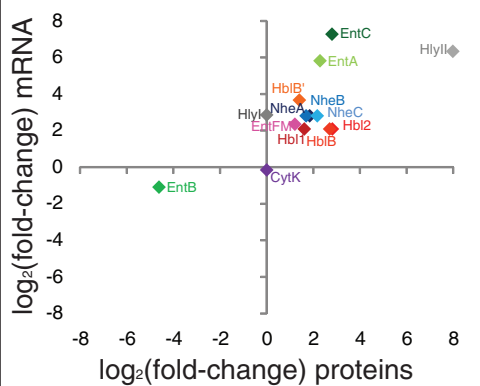 & 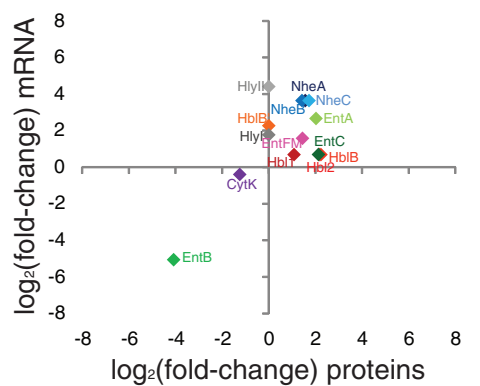 & 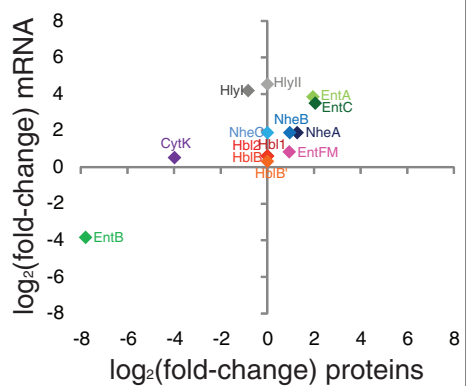 \\
\hline
\end{tabular}

Fig. 2 - Correlation of mRNA level changes with protein abundance changes in $\triangle$ ohrA and $\triangle$ ohrR cells relative to wild-type cells when grown under low-ORP anaerobiosis, high-ORP aerobiosis, and aerobiosis. Relative transcript abundance data are plotted against relative exoprotein abundance data.

and octameric species showed higher apparent molecular weights at the highest CHP concentrations than those detected with lower CHP concentrations.

The reversibility of CHP oxidation was assayed by incubating OhrR with either DTT $\left(E_{0}^{\prime}=-0.33 \mathrm{~V}\right.$, [53]) or free dihydrolipoate (DHLA, $\left(E^{\prime}{ }_{0}=-0.32 \mathrm{~V}\right)$, [54]) as a dithiol/disulfide redox component, or the three major low-molecular-weight (LMW) monothiols found in B. cereus [55], i.e. cysteine (Cys, $E_{0}^{\prime}=-0.21 \mathrm{~V}$ ), bacillithiol (BSH, standard redox potential is unknown) and Coenzyme $\mathrm{A}\left(\mathrm{CoASH}, \mathrm{E}^{\prime}{ }_{0}=-0.33 \mathrm{~V}\right)$. Fig. $3 \mathrm{~B}$ shows representative nonreducing SDS-PAGE gels where dose-dependent samples were resolved. Whatever the reductant, OhrR reduction led to appearance of monomeric OhrR concomitantly with i) first, the disappearance of the faster-migrating form of the OhrR covalent dimer, and ii) second, bleaching of the slower band. These data indicated that the rigid and relaxed conformations of the covalent OhrR dimers differ in terms of the presence of disulfide bridges. The more rigid form may result from a reversible intramolecular disulfide bridge that is easily accessible to the reductant. The relaxed form may result from a less-accessible intermolecular disulfide bridge. As shown in Fig. 3, we found that the dithiol, DHLA, is a stronger reductant for the OhrR protein than DTT and the monothiols, Cys, BSH and CoASH. Of the three LMW monothiols, Cys appeared to be the strongest reductant. Finally, we demonstrated that $B$. cereus OhrR is mainly a noncovalent dimer in its reduced form and a covalent dimer in its oxidized form. We also showed that DHLA and
LMW thiols may participate, in vivo, in the recovery of reduced OhrR from the oxidized form.

3.5. The redox state of OhrR is critical for its binding to toxin gene promoters

In order to determine if reduced OhrR binds directly to toxin gene promoter regions to mediate transcriptional repression or activation, electrophoretic mobility shift assays (EMSA) were performed using DTT-reduced, purified OhrR and DNA fragments corresponding to promoter regions of the toxinrelated operons or genes. Because of its very large size, the promoter region of $\mathrm{hbl}$ was divided into two overlapping fragments of $636 \mathrm{bp}$ (hbl1) and $610 \mathrm{bp}$ (hbl2). Binding specificity was shown by the absence of a mobility shift with the negative control performed with the ssu promoter region (Fig. 4A), the disappearance of protein-nucleic acid complexes upon addition of an excess (50-fold) of unlabeled heterologous promoter region, and the maintenance of protein-nucleic acid complexes in competition assays using a ten-fold excess of unlabeled negative control (data not shown). Fig. 4A shows that reduced OhrR bound specifically to all of the 12 promoter regions assayed except entFM. Reduced OhrR showed markedly different behavior in gel-shift titration assays depending on the promoter region: (i) OhrR bound to the entB promoter region in an ordered manner, producing a first protein-nucleic acid species faintly visible from $0.05 \mu \mathrm{M}$ to clearly visible at $0.4 \mu \mathrm{M}$ OhrR, and then a second, slowly moving species at concentrations above $0.4 \mu \mathrm{M}$; (ii) increasing amounts of OhrR 
Version définitive du manuscrit publiée dans / Final version of the manuscript published in :

Journal of Proteomics (2013), Vol. 94, p. 527-539, DOI: 10.1016/j.prot.2013.10.024

Journal homepage: www.elsevier.com/locateljprot

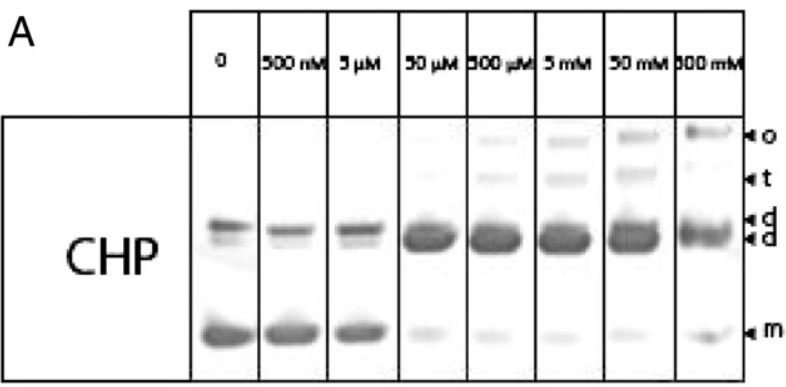

3.6. OhrR and OhrA modulate the inhibitory effect of the B. cereus exoproteome on the growth of Caco-2 cells

We showed previously that the B. cereus exoproteome had inhibitory effects on the cellular growth of human colonic epithelial Caco-2 cells, which are recognized as a model of the intestinal mucosa [56]. To evaluate the contribution of OhrR and OhrA to the anti-proliferative activity of the B. cereus exoproteome, we compared the inhibitory effects of $\Delta o h r A$, $\Delta$ ohrR and wild-type culture filtrate supernatant on Caco-2 cell growth. Two exoprotein concentrations were assayed: $1.6 \pm 0.1 \mathrm{mg} / \mathrm{L}$ and $0.3 \pm 0.1 \mathrm{mg} / \mathrm{L}$ (Table 2). At the higher exoprotein concentration, the $\Delta$ ohrR culture filtrate supernatant abolished Caco-2 cell growth in all cases while the $\Delta$ ohrA culture filtrate supernatant abolished Caco- 2 cell growth only when prepared from low-ORP, anaerobically grown cells. At the lower exoprotein concentration the inhibitory effects were less pronounced, resulting in a poor difference between the $\Delta$ ohrA and wild-type culture filtrate supernatants, whatever the conditions. However, the $\Delta$ ohrR culture filtrate supernatant retained its high inhibitory activity when prepared from low-ORP, anaerobically grown cells, and exhibited a higher inhibitory activity than the high concentration culture filtrate supernatant of the wild-type strain obtained from high-ORP, anaerobically or aerobically grown cells. Taken together, these data indicate that OhrR restricts the Caco-2-antiproliferative activity of the B. cereus exoproteome, whatever the growth conditions - markedly so when the $B$. cereus cells are grown under low-ORP anaerobiosis. Similarly to OhrR, but to a lesser extent, OhrA restricts the Caco-2-antiproliferative activity of the B. cereus exoproteome when bacteria are grown under low-ORP anaerobiosis.

3.7. Changes in toxin abundance levels explain the OhrR- and OhrA-dependent inhibitory effect of the B. cereus exoproteome on the growth of Caco-2 cells

Fig. 3 - SDS-PAGE in nonreducing conditions for oxidized and reduced OhrR samples. Both NuPAGE SDS-PAGE 4-12\% polyacrylamide gels were stained with SimplyBlue SafeStain (Invitrogen). Panel A. Purified OhrR oxidized with 0, $500 \mathrm{nM}$, $5 \mu \mathrm{M}, 50 \mu \mathrm{M}, 500 \mu \mathrm{M}, 5 \mathrm{mM}, 50 \mathrm{mM}$ and $500 \mathrm{mM} \mathrm{CHP}$, respectively. Panel B. Oxidized OhrR reduced with 0, 0.05, 0.1, $0.5,1,5,10$ and $25 \mathrm{mM}$ cysteine (Cys), bacillithiol (BSH), Coenzyme A (CoASH), dihydrolipoate (DHLA) and DTT. The arrows on the left indicate the presence of monomers ( $m)$, dimers (d), trimers $(t)$ and oligomers $(0)$.

resulted in a gradual decrease of hbl1, hbl2 and nhe DNA mobility above $0.8,0.2$, and $0.8 \mu \mathrm{M}$, respectively, and (iii) higher concentrations of reduced OhrR were needed to form DNA complexes with hbl1 and hbl2, hblB, nhe, hlyI, hlyII, entA and entC promoter regions than with its own promoter region. Adding $50 \mu \mathrm{M}$ CHP to the EMSA reaction mixtures abolished the binding of $1 \mu \mathrm{M}$ reduced OhrR to its own promoter and to all the toxin gene promoters except entB. Only the faster-migrating protein-entB species was observed with CHP-oxidized OhrR (Fig. 4A). The initial binding behavior was recovered after addition of $100 \mu \mathrm{M}$ DTT, whatever the promoter region (data not shown).

We showed that OhrR, and to a lesser extent OhrA, impact both the toxin abundance level (Table 1) and the inhibitory effect of the B. cereus exoproteome on Caco-2 cell growth (Table 2). To determine whether changes in toxin levels could explain the differences between the antiproliferative activities of $\Delta \mathrm{ohrR}, \Delta \mathrm{ohr} \mathrm{A}$ and the wild-type exoproteome, we performed a principal component analysis (PCA). Variables were organized as active and supplementary. The active variable group included the content of each toxin-related protein as evaluated by our shotgun proteomic approach and the supplementary variable group included the percentage of growth inhibition on Caco-2 cells (noted as cytotoxicity in Fig. 5). The corresponding data and analytical details are given in Table S5. Projection of the variables on the PC1-PC2 plane synthesized the PCA (Fig. 5) and shows that (i) by restricting the exoproteome to toxin-related protein we reconstructed the variability of "cytotoxicity", (ii) the variability of a subset of toxin components, namely EntA, EntB, EntC, EntFM, HblL1, HblL2 and HblB, NheA, NheB and NheC, was the major contributor to the differences between mutant and wild-type strain anti-proliferative activity, whatever the redox growth conditions, (iii) EntB variability was negatively correlated with the variability of EntA, EntC, EntFM, HblL1, HblL2 and HblB, 
Version définitive du manuscrit publiée dans / Final version of the manuscript published in :

Journal of Proteomics (2013), Vol. 94, p. 527-539, DOI: 10.1016/j.prot.2013.10.024

Journal homepage: www.elsevier.com/locateljprot

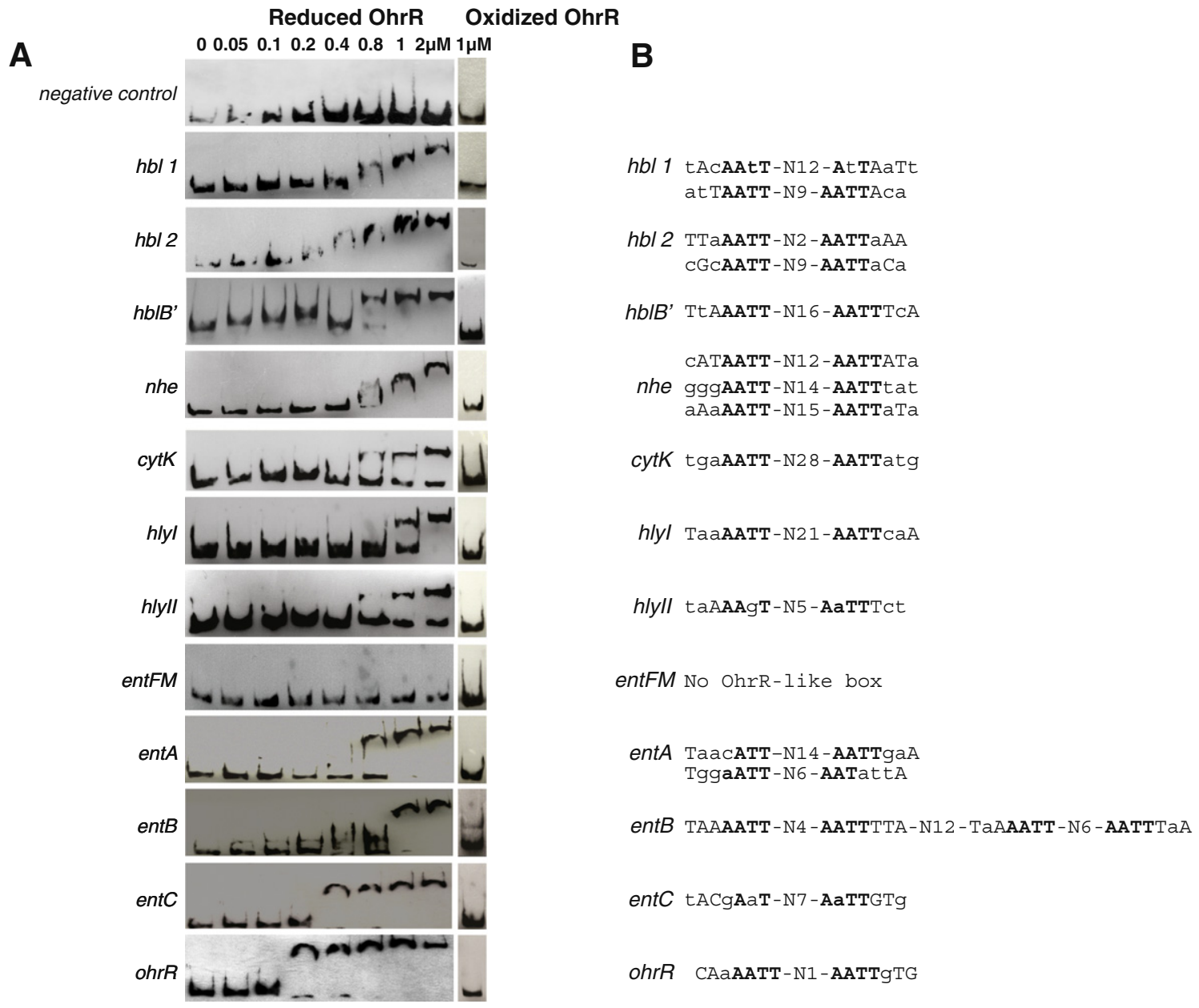

Fig. 4 - Binding of reduced and CHP-oxidized OhrR to toxin promoter regions determined by EMSA. Panel A. Biotin-labeled PCR products ( $2 \mathrm{nM}$ ) corresponding to $h b l 1, h b l 2, h b l B$, hhe, cytK, hlyI, hlyII, entFM, entA, entB, entC, ohrR and a negative control (a fragment of the ssuRNA BCO007 sequence) were bound with $0,0.05,0.1,0.2,0.4,0.8,1$ and $2 \mu \mathrm{M}$ reduced OhrR and $1 \mu \mathrm{M}$ CHP-oxidized OhrR. Panel B. Putative AT-rich OhrR binding sites upstream of toxin coding sequences are shown. Inverted repeats are shown in capitals. The core tetranucleotide AATT sequence of the consensus binding site of OhrR from other bacteria is indicated in bold.

NheA, NheB and NheC, and (iv) the variability in "cytotoxicity" was highly negatively correlated with EntB variability, whatever the redox growth condition, and highly positively correlated with HlyII variability under low-ORP anaerobiosis.
From these results, and those reported in Table 2, we concluded that EntB is the toxin which contributes the most to the overall difference between $\Delta o h r R$ and wild-type antiproliferative activities on Caco-2 cells.

Table 2 - Mean percentage of Caco-2 cell growth inhibition by B. cereus exoproteomes.

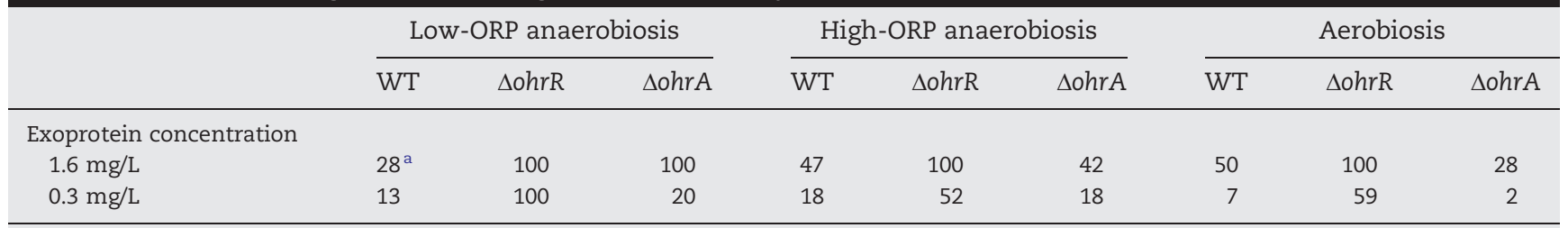

${ }^{a}$ Percentage of Caco-2 cell growth inhibition was measured after 96 h-incubation with exoproteomes containing 1.6 and $0.3 \mathrm{mg} / \mathrm{L}$ of proteins. Exoproteomes were prepared from cells grown under low-ORP anaerobiosis, high-ORP anaerobiosis, and aerobiosis. Data are the means of 6 values. For clarity, standard deviations (below 10\%) are not shown. 
Version définitive du manuscrit publiée dans / Final version of the manuscript published in :

Journal of Proteomics (2013), Vol. 94, p. 527-539, DOI: 10.1016/j.prot.2013.10.024

Journal homepage: www.elsevier.com/locate/jprot

Low-ORP anaerobiosis

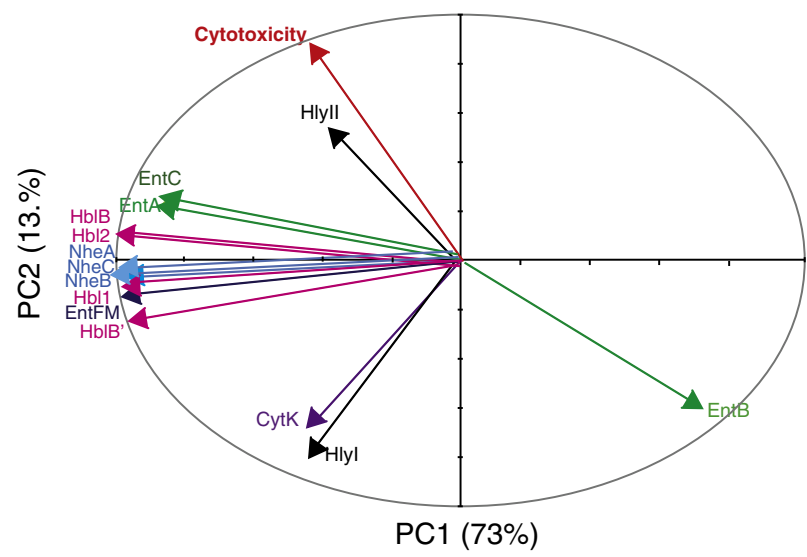

High-ORP anaerobiosis
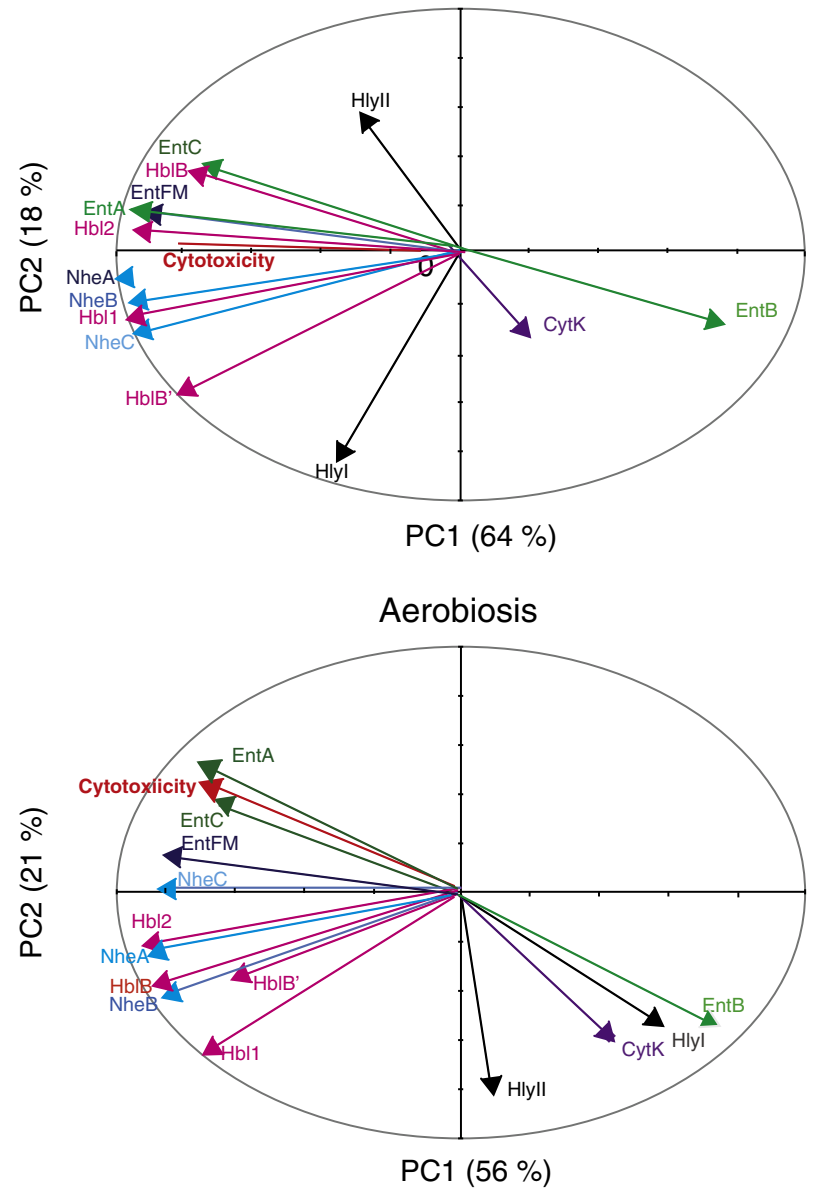

Fig. 5 - Correlation circles for principal component analysis (PCA) on toxin-related proteins of wild-type and $\triangle \mathrm{ohrA}$ and $\triangle$ ohrR mutant strains. Vectors are the loadings on PC1 (x-axis) and PC2 (y-axis). Vector length indicates the strength of the relationship and the angle between two vectors gives the degree of correlation (adjacent = highly correlated, orthogonal $\left(90^{\circ}\right)=$ uncorrelated, and opposite $\left(180^{\circ}\right)=$ negatively correlated). For details, see Table $\mathbf{S 5}$.

\section{Discussion}

Similarly to its orthologs in other bacteria, B. cereus OhrR functions as a transcriptional regulator that binds to its own promoter in its dimeric, reduced form [52,57-60]. Unlike most of its orthologs, B. cereus OhrR may regulate genes other than ohrRA. Notably, we found that OhrR may regulate, directly or indirectly, the transcription of all operons and genes encoding toxin-related proteins that have been identified in the B. cereus exoproteome. Based on our EMSA data (Fig. 4), OhrR does not directly control the transcription of the entFM locus. However, entFM expression was increased in the $\Delta$ ohrR mutant (Table 2). This indicates that the OhrR-dependent regulation of entFM transcription is indirect. Transcriptomic analysis indicated little, if any, change in cytK mRNA in the absence of OhrR, suggesting a weak transcriptional activity of OhrR on cytK in our growth conditions. We also demonstrated a striking dissimilarity between OhrR-dependent regulation of entB and of other toxin-related genes, in that: (i) OhrR was an activator of entB and a repressor of other toxin- and putative toxin-encoding genes, and (ii) oxidized OhrR is capable of binding entB but did not form a $2 \times$ dimeric complex, as observed with the reduced form. Previous studies have defined the consensus binding site of OhrR from other bacteria as an AT-rich, palindromic sequence of approximately $2 \times 7$ nucleotides separated by a variable-length spacer of 1 to 17 nucleotides [58]. Inspection of the nucleotide sequences for the promoter regions tested here indicated the recurrent presence of AT-rich sequences. A perfect inverted-repeat motif (TAAAATT-N ${ }_{4}$-AATTTTA) is present in the entB promoter region and could be a good candidate as the binding site for OhrR (Fig. 4B). Another AT-rich dual motif showing only one single nucleotide deviation (TaAAATT-N6-AATTTaA) flanks the first binding site. The presence of tandem binding sites on entB DNA and the presence of two migrating species in the corresponding EMSA (Fig. 4A) suggest occupation of one binding site at a moderately low concentration of reduced OhrR and occupation of both DNA binding sites at a higher concentration of reduced OhrR. This indicates that one entB DNA molecule could bind two noncovalent dimers of OhrR (reduced form) and only one covalent-linked dimer of OhrR (oxidized form), as only the faster-migrating protein-DNA complex was observed with the oxidized form. For ohrR, we found two seven-nucleotide motifs that are almost perfect inverted repeats (Fig. 4B) but differ in sequence compared with the other motifs identified. This could explain why B. cereus OhrR showed lower DNA binding affinity to its own promoter than did its orthologs [52,61]. There are two other, major possible explanations. First, B. cereus OhrR differs structurally from its orthologs, and second, we chose a longer target DNA to span the entire ohrRA promoter region. Four putative binding sites were found in the $h b l$ promoter region (two in $h b l 1$ and two in $h b l 2)$, three were found in the nhe promoter region, two in entA, and one in the hblB', cytK, hlyII, hlyI and entC promoter regions, while no motif could be detected within the entFM promoter region. We noted that putative binding sites in cytK, hlyI and hlyII differed significantly from the consensus described in other bacteria, because the two binding motifs were either separated by more than 17 nucleotides or did 
not involve the core tetranucleotide AATT sequence. Accordingly, EMSA data showed that reduced OhrR bound to cytK, hlyI and hlyII promoter regions with a lower affinity than to the other toxin gene promoter regions. Thus, direct binding of OhrR to promoter regions for toxin-related proteins may depend on both its redox state and its ATrich target binding site. Globally, OhrR binding to toxin promoter regions required a high protein concentration in our in vitro analysis. Given that toxin gene expression is multi-regulated, it is possible that the stability of the toxin promoter-OhrR complex requires several additional protein partners in B. cereus [62].

In addition to toxins, OhrR regulates the abundance level of flagellins (Table S4). Inspection of the promoter region of the fla operon [42], which encodes flagellins A, B, and $C$, led to the identification of an inverted repeat sequence (TACAATT-N8-AATTGAT) highly resembling the OhrR-like, AT-rich box found in toxin promoter regions. OhrR may, thus, regulate motility by directly modulating fla gene expression levels. Our previous analysis of the B. cereus intracellular proteome showed significant changes in the abundance levels of the pleiotropic regulators, SinR, AbrB, CcpA and CodY [39]. These regulators were recognized as modulating toxin production and/or motility [31,33,63,64]. Inspection of the promoter regions of their genes indicated a putative OhrR-like box, except for CcpA (Fig. S3). Thus, OhrR could orchestrate the expression of virulence determinants in $B$. cereus, both directly, by modulating toxin and flagella gene expression, and indirectly, by impacting key regulatory circuits. Several studies converge to suggest the existence of a connection between motility and cytotoxicity in B. cereus, as is the case for several other pathogenic bacteria [65-69]. Our findings suggest that OhrR is a key player in this connection.

As for OhrR, OhrA controls the abundance level of toxin-related proteins in the B. cereus exoproteome in a redoxand toxin-dependent manner (Tables 1 and S4). Our data suggest that OhrA may act as a post-transcriptional regulator by controlling the stability and/or correct localization of toxinrelated proteins in a protein- and redox-dependent manner. Given that NheC (NP_831584), unlike NheA (NP_831582) and NheB (NP_831583), contains two cysteines and thus features thiols vulnerable to oxidative modifications, OhrA could be needed to fully protect NheC against ROS damage and to sustain high-level secretion of NheC via the Sec pathway under aerobiosis. Unlike other toxins, HlyI has been recognized as a thiol-activated cytolysin [70]. This could offer two different targets for OhrA control compared with other toxins and could also explain why HlyI was positively controlled by OhrA, whatever the conditions. Why does HlyII escape redoxdependent OhrA control? The answer is probably linked to the existence of a very different control of HlyII export than for the other toxins [32]. Clearly the redox-dependent OhrA control of toxin level is a complex process and needs further investigation. Our exoproteomic analyses have, however, revealed a critical requirement for OhrA activity when OhrR is present, to maintain similar levels of toxin (except HlyII) whatever the conditions. Finally, as for OhrR activity, the activity of OhrA appeared to be higher under low-ORP anaerobiosis than under high-ORP anaerobiosis and aerobiosis.
Earlier studies (reviewed in [5]) have demonstrated that the level of toxin gene expression plays a major role in determining the cytotoxic potential of a bacterial strain, thus relegating the presence of a specific toxin to a less important role. Our study suggests that EntB is a crucial determinant of the OhrR-dependent inhibitory effect of the B. cereus exoproteome on model intestinal cell lines. EntB is structurally similar to both EntA and EntC [6] and we observed here an OhrRdependent negative correlation between the abundance level of EntB and those of EntA and EntC and Nhe, Hbl and EntFM. Evidently, further intensive work is now required to elucidate the function of EntB, which could be crucial in triggering EntA and EntC- and Nhe, $\mathrm{Hbl}$ and EntFM-dependent cytotoxicity of the $B$. cereus exoproteome.

\section{Conclusion}

In our previous study, we proposed that B. cereus restricts its fermentative growth under low-ORP anaerobiosis and sustains efficient aerobic respiratory metabolism, motility, and stress response via OhrRA-dependent intracellular proteome remodeling [39]. Here, we found that OhrRA plays a major role in toxinogenesis, especially under low-ORP anaerobiosis. From this aspect, B. cereus OhrRA is unique compared with other OhrRAsystems $[39,51,52]$. In the natural evolutionary context, the $B$. cereus OhrRA system appears to have been shaped to facilitate $B$. cereus survival and toxinogenesis under various redox growth conditions, such as those encountered in human intestine.

Supplementary data to this article can be found online at http://dx.doi.org/10.1016/j.jprot.2013.10.024.

\section{Acknowledgments}

The authors express special thanks to Mathilde Gauchier for help with the EMSA experiments. This work was supported by the Commissariat à l'Energie Atomique et aux Energies alternatives and the Université d'Avignon et des Pays de Vaucluse. GC was the recipient of a fellowship from the Ministère de la Recherche et de l'Enseignement Supérieur.

\section{R E F E R E N C E S}

[1] Bottone EJ. Bacillus cereus, a volatile human pathogen. Clin Microbiol Rev 2010;23:382-98.

[2] Logan NA. Bacillus and relatives in foodborne illness. J Appl Microbiol 2012;112:417-29.

[3] Ceuppens S, Uyttendaele M, Drieskens K, Heyndrickx M, Rajkovic A, Boon N, et al. Survival and germination of Bacillus cereus spores during in vitro simulation of gastrointestinal transit occurred without outgrowth and enterotoxin production. Appl Environ Microbiol 2012;78:7698-705.

[4] Ceuppens S, Uyttendaele M, Drieskens K, Rajkovic A, Boon N, Wiele TV. Survival of Bacillus cereus vegetative cells and spores during in vitro simulation of gastric passage. J Food Prot 2012;75:690-4.

[5] Stenfors Arnesen LP, Fagerlund A, Granum PE. From soil to gut: Bacillus cereus and its food poisoning toxins. FEMS Microbiol Rev 2008;32:579-606. 
[6] Clair G, Roussi S, Armengaud J, Duport C. Expanding the known repertoire of virulence factors produced by Bacillus cereus through early secretome profiling in three redox conditions. Mol Cell Proteomics 2010;9:1486-98.

[7] Beecher DJ, Schoeni JL, Wong AC. Enterotoxic activity of hemolysin BL from Bacillus cereus. Infect Immun 1995;63:4423-8.

[8] Didier A, Dietrich R, Gruber S, Bock S, Moravek M, Nakamura $\mathrm{T}$, et al. Monoclonal antibodies neutralize Bacillus cereus Nhe enterotoxin by inhibiting ordered binding of its three exoprotein components. Infect Immun 2012;80:832-8.

[9] Phung D, Granum PE, Dietrich R, Martlbauer E, Hardy SP. Inhibition of cytotoxicity by the Nhe cytotoxin of Bacillus cereus through the interaction of dodecyl maltoside with the NheB component. FEMS Microbiol Lett 2012;330:98-104.

[10] Fagerlund A, Lindback T, Granum PE. Bacillus cereus cytotoxins $\mathrm{Hbl}$, Nhe and CytK are secreted via the Sec translocation pathway. BMC Microbiol 2010;10:304.

[11] Hardy SP, Lund T, Granum PE. CytK toxin of Bacillus cereus forms pores in planar lipid bilayers and is cytotoxic to intestinal epithelia. FEMS Microbiol Lett 2001;197:47-51.

[12] Boonchai N, Asano SI, Bando H, Wiwat C. Study on cytotoxicity and nucleotide sequences of enterotoxin FM of Bacillus cereus isolated from various food sources. J Med Assoc Thai 2008;91:1425-32.

[13] Tran SL, Guillemet E, Gohar M, Lereclus D, Ramarao N. CwpFM (EntFM) is a Bacillus cereus potential cell wall peptidase implicated in adhesion, biofilm formation, and virulence. J Bacteriol 2010;192:2638-42.

[14] Andreeva ZI, Nesterenko VF, Yurkov IS, Budarina ZI, Sineva EV, Solonin AS. Purification and cytotoxic properties of Bacillus cereus hemolysin II. Protein Expr Purif 2006;47:186-93.

[15] Baida G, Budarina ZI, Kuzmin NP, Solonin AS. Complete nucleotide sequence and molecular characterization of hemolysin II gene from Bacillus cereus. FEMS Microbiol Lett 1999;180:7-14.

[16] Kreft J, Berger H, Hartlein M, Muller B, Weidinger G, Goebel W. Cloning and expression in Escherichia coli and Bacillus subtilis of the hemolysin (cereolysin) determinant from Bacillus cereus. J Bacteriol 1983;155:681-9.

[17] Minnaard J, Humen M, Perez PF. Effect of Bacillus cereus exocellular factors on human intestinal epithelial cells. J Food Prot 2001;64:1535-41.

[18] Duan Q Zhou M, Zhu L, Zhu G. Flagella and bacterial pathogenicity. J Basic Microbiol 2012;53:1-8.

[19] Hirst RA, Gosai B, Rutman A, Guerin CJ, Nicotera P, Andrew PW, et al. Streptococcus pneumoniae deficient in pneumolysin or autolysin has reduced virulence in meningitis. J Infect Dis 2008;197:744-51.

[20] Wang L, Lin M. A novel cell wall-anchored peptidoglycan hydrolase (autolysin), IspC, essential for Listeria monocytogenes virulence: genetic and proteomic analysis. Microbiology 2008;154:1900-13.

[21] Guillemet E, Cadot C, Tran SL, Guinebretiere MH, Lereclus D, Ramarao N. The InhA metalloproteases of Bacillus cereus contribute concomitantly to virulence. J Bacteriol 2010;192:286-94.

[22] Vellasamy KM, Vasu C, Puthucheary SD, Vadivelu J. Comparative analysis of extracellular enzymes and virulence exhibited by Burkholderia pseudomallei from different sources. Microb Pathog 2009;47:111-7.

[23] Zawadzka AM, Abergel RJ, Nichiporuk R, Andersen UN, Raymond KN. Siderophore-mediated iron acquisition systems in Bacillus cereus: identification of receptors for anthrax virulence-associated petrobactin. Biochemistry 2009;48:3645-57.

[24] Henderson B, Martin A. Bacterial moonlighting proteins and bacterial virulence. Curr Top Microbiol Immunol 2011;358:155-213.
[25] Henderson B, Martin A. Bacterial virulence in the moonlight: multitasking bacterial moonlighting proteins are virulence determinants in infectious disease. Infect Immun 2011;79:3476-91.

[26] Laouami S, Messaoudi K, Alberto F, Clavel T, Duport C. Lactate dehydrogenase A promotes communication between carbohydrate catabolism and virulence in Bacillus cereus. J Bacteriol 2011;193:1757-66.

[27] Armengaud J, Christie-Oleza J, Clair G, Malard V, Duport C. Exoproteomics: exploring the world around the system. Expert Rev Proteomics 2012;9:562-75.

[28] Ceuppens S, Rajkovic A, Heyndrickx M, Tsilia V, Van De Wiele $\mathrm{T}$, Boon N, et al. Regulation of toxin production by Bacillus cereus and its food safety implications. Crit Rev Microbiol 2011;37:188-213

[29] Gohar M, Faegri K, Perchat S, Ravnum S, Okstad OA, Gominet $\mathrm{M}$, et al. The PlcR virulence regulon of Bacillus cereus. PLoS One 2008;3:e2793.

[30] Salamitou S, Ramisse F, Brehelin M, Bourguet D, Gilois N, Gominet $\mathrm{M}$, et al. The plcR regulon is involved in the opportunistic properties of Bacillus thuringiensis and Bacillus cereus in mice and insects. Microbiology 2000;146(Pt 11):2825-32.

[31] Lindback T, Mols M, Basset C, Granum PE, Kuipers OP, Kovacs AT. CodY, a pleiotropic regulator, influences multicellular behaviour and efficient production of virulence factors in Bacillus cereus. Environ Microbiol 2012;14:2233-46.

[32] Sineva E, Shadrin A, Rodikova EA, Andreeva-Kovalevskaya ZI, Protsenko AS, Mayorov SG, et al. Iron regulates expression of Bacillus cereus hemolysin II via global regulator Fur. J Bacteriol 2012;194:3327-35.

[33] van der Voort M, Kuipers OP, Buist G, de Vos WM, Abee T. Assessment of CcpA-mediated catabolite control of gene expression in Bacillus cereus ATCC 14579. BMC Microbiol 2008;8:62.

[34] Duport C, Zigha A, Rosenfeld E, Schmitt P. Control of enterotoxin gene expression in Bacillus cereus F4430/73 involves the redox-sensitive ResDE signal transduction system. J Bacteriol 2006;188:6640-51.

[35] Esbelin J, Armengaud J, Zigha A, Duport C. ResDE-dependent regulation of enterotoxin gene expression in Bacillus cereus: evidence for multiple modes of binding for ResD and interaction with Fnr. J Bacteriol 2009;191:4419-26.

[36] Esbelin J, Jouanneau Y, Armengaud J, Duport C. ApoFnr binds as a monomer to promoters regulating the expression of enterotoxin genes of Bacillus cereus. J Bacteriol 2008;190:4242-51.

[37] Messaoudi K, Clavel T, Schmitt P, Duport C. Fnr mediates carbohydrate-dependent regulation of catabolic and enterotoxin genes in Bacillus cereus F4430/73. Res Microbiol 2010;161:30-9.

[38] Zigha A, Rosenfeld E, Schmitt P, Duport C. The redox regulator Fnr is required for fermentative growth and enterotoxin synthesis in Bacillus cereus F4430/73. J Bacteriol 2007;189:2813-24.

[39] Clair G, Armengaud J, Duport C. Restricting fermentative potential by proteome remodeling: an adaptive strategy evidenced in Bacillus cereus. Mol Cell Proteomics 2012;11 [M111 013102].

[40] Dubbs JM, Mongkolsuk S. Peroxiredoxins in bacterial antioxidant defense. Subcell Biochem 2007;44:143-93.

[41] Panmanee W, Vattanaviboon P, Poole LB, Mongkolsuk S. Novel organic hydroperoxide-sensing and responding mechanisms for OhrR, a major bacterial sensor and regulator of organic hydroperoxide stress. J Bacteriol 2006;188:1389-95.

[42] Ivanova N, Sorokin A, Anderson I, Galleron N, Candelon B, Kapatral V, et al. Genome sequence of Bacillus cereus and comparative analysis with Bacillus anthracis. Nature 2003;423:87-91. 
[43] Rosenfeld E, Duport C, Zigha A, Schmitt P. Characterization of aerobic and anaerobic vegetative growth of the food-borne pathogen Bacillus cereus F4430/73 strain. Can J Microbiol 2005;51:149-58.

[44] Duport C, Thomassin S, Bourel G, Schmitt P. Anaerobiosis and low specific growth rates enhance hemolysin $\mathrm{BL}$ production by Bacillus cereus F4430/73. Arch Microbiol 2004;182:90-5.

[45] Dupierris V, Masselon C, Court M, Kieffer-Jaquinod S, Bruley C. A toolbox for validation of mass spectrometry peptides identification and generation of database: IRMa. Bioinformatics 2009;25:1980-1.

[46] Carvalho PC, Fischer JS, Chen EI, Yates III JR, Barbosa VC. PatternLab for proteomics: a tool for differential shotgun proteomics. BMC Bioinformatics 2008;9:316.

[47] Rakotomalala R. TANAGRA: un logiciel gratuit pour l'enseignement et la recherche. Actes de EGC, RNTI-E-3, 2; 2005. p. 697-702.

[48] Armengaud J, Fernandez B, Chaumont V, Rollin-Genetet F, Finet S, Marchetti C, et al. Identification, purification, and characterization of an eukaryotic-like phosphopantetheine adenylyltransferase (coenzyme A biosynthetic pathway) in the hyperthermophilic archaeon Pyrococcus abyssi. J Biol Chem 2003;278:31078-87.

[49] Armengaud J, Urbonavicius J, Fernandez B, Chaussinand G, Bujnicki JM, Grosjean H. N2-methylation of guanosine at position 10 in tRNA is catalyzed by a THUMP domain-containing, S-adenosylmethionine-dependent methyltransferase, conserved in Archaea and Eukaryota. J Biol Chem 2004;279:37142-52.

[50] Burts ML, Williams WA, DeBord K, Missiakas DM. EsxA and EsxB are secreted by an ESAT-6-like system that is required for the pathogenesis of Staphylococcus aureus infections. Proc Natl Acad Sci U S A 2005;102:1169-74.

[51] Dubbs JM, Mongkolsuk S. Peroxide-sensing transcriptional regulators in bacteria. J Bacteriol 2012;194:5495-503.

[52] Caswell CC, Baumgartner JE, Martin DW, Roop II RM. Characterization of the organic hydroperoxide resistance system of Brucella abortus 2308. J Bacteriol 2012;194:5065-72.

[53] Cleland WW. Dithiothreitol, a new protective reagent for Sh groups. Biochemistry 1964;3:480-2.

[54] Kagan VE, Shvedova A, Serbinova E, Khan S, Swanson C, Powell R, et al. Dihydrolipoic acid-a universal antioxidant both in the membrane and in the aqueous phase. Reduction of peroxyl, ascorbyl and chromanoxyl radicals. Biochem Pharmacol 1992;44:1637-49.

[55] Newton GL, Rawat M, La Clair JJ, Jothivasan VK, Budiarto T, Hamilton CJ, et al. Bacillithiol is an antioxidant thiol produced in Bacilli. Nat Chem Biol 2009;5:625-7.

[56] Sambuy Y, De Angelis I, Ranaldi G, Scarino ML, Stammati A, Zucco F. The Caco-2 cell line as a model of the intestinal barrier: influence of cell and culture-related factors on Caco-2 cell functional characteristics. Cell Biol Toxicol 2005;21:1-26.

[57] Atichartpongkul S, Fuangthong M, Vattanaviboon P, Mongkolsuk S. Analyses of the regulatory mechanism and physiological roles of Pseudomonas aeruginosa OhrR, a transcription regulator and a sensor of organic hydroperoxides. J Bacteriol 2010;192:2093-101.

[58] Chuchue T, Tanboon W, Prapagdee B, Dubbs JM, Vattanaviboon P, Mongkolsuk S. ohrR and ohr are the primary sensor/regulator and protective genes against organic hydroperoxide stress in Agrobacterium tumefaciens. J Bacteriol 2006;188:842-51.

[59] Fuangthong M, Atichartpongkul S, Mongkolsuk S, Helmann JD. OhrR is a repressor of ohrA, a key organic hydroperoxide resistance determinant in Bacillus subtilis. J Bacteriol 2001;183:4134-41.

[60] Panmanee W, Vattanaviboon P, Eiamphungporn W, Whangsuk W, Sallabhan R, Mongkolsuk S. OhrR, a transcription repressor that senses and responds to changes in organic peroxide levels in Xanthomonas campestris pv. phaseoli. Mol Microbiol 2002;45:1647-54.

[61] Oh SY, Shin JH, Roe JH. Dual role of OhrR as a repressor and an activator in response to organic hydroperoxides in Streptomyces coelicolor. J Bacteriol 2007;189:6284-92.

[62] Esbelin J, Jouanneau Y, Duport C. Bacillus cereus Fnr binds a [4Fe-4S] cluster and forms a ternary complex with ResD and PlcR. BMC Microbiol 2012;12:125.

[63] Frenzel E, Doll V, Pauthner M, Lucking G, Scherer S, Ehling-Schulz M. CodY orchestrates the expression of virulence determinants in emetic Bacillus cereus by impacting key regulatory circuits. Mol Microbiol 2012;85:67-88.

[64] Pflughoeft KJ, Sumby P, Koehler TM. Bacillus anthracis sin locus and regulation of secreted proteases. J Bacteriol 2011;193:631-9.

[65] Bouillaut L, Ramarao N, Buisson C, Gilois N, Gohar M, Lereclus $\mathrm{D}$, et al. FlhA influences Bacillus thuringiensis PlcR-regulated gene transcription, protein production, and virulence. Appl Environ Microbiol 2005;71:8903-10.

[66] Callegan MC, Kane ST, Cochran DC, Gilmore MS, Gominet M, Lereclus D. Relationship of plcR-regulated factors to Bacillus endophthalmitis virulence. Infect Immun 2003;71:3116-24.

[67] Ghelardi E, Celandroni F, Salvetti S, Ceragioli M, Beecher DJ, Senesi S, et al. Swarming behavior of and hemolysin BL secretion by Bacillus cereus. Appl Environ Microbiol 2007;73:4089-93.

[68] Gohar M, Okstad OA, Gilois N, Sanchis V, Kolsto AB, Lereclus D. Two-dimensional electrophoresis analysis of the extracellular proteome of Bacillus cereus reveals the importance of the PlcR regulon. Proteomics 2002;2:784-91.

[69] Ramarao N, Lereclus D. Adhesion and cytotoxicity of Bacillus cereus and Bacillus thuringiensis to epithelial cells are FlhA and PlcR dependent, respectively. Microbes Infect 2006;8:1483-91.

[70] Brillard J, Lereclus D. Characterization of a small PlcR-regulated gene co-expressed with cereolysin O. BMC Microbiol 2007;7:52. 